\title{
Gamification Design Elements to Enhance Adolescent Motivation in Diagnosing Depression
}

\author{
https://doi.org/10.3991/ijim.v15i10.21137 \\ Nurul Fasihah Jamaludin \\ Ministry of Education, Cyberjaya, Malaysia \\ Tengku Siti Meriam Tengku Wook (®), Siti Fadzilah Mat Noor, \\ Faizan Qamar \\ Universiti Kebangsaan Malaysia (UKM), Bangi, Malaysia \\ tsmeriameukm.edu.my
}

\begin{abstract}
Depression is a critical public health problem, mainly when it affects young people (adolescents). This condition is most challenging to detect in this group because they tend to think about other people's negative assumptions. Adolescents with depressive symptoms refuse to seek professional help due to their stigma and their future if they were labeled as depressed teenagers. Depression is a severe mental issue that should be detected from an early stage so that the problem can be curbed and resolved immediately. Diagnosis should be carried out to assess mental health, followed by referral to professional help. This study aims to motivate adolescents to diagnose depression levels through gamification techniques. Fifty-three secondary students participated in a survey designed in this study to measure motivation enhancement factors. The result of this study was used to develop a depression diagnosis model. The proposed model applied a gamification design technique consisting of three main ideas: gamification elements, user types, and motivational elements. This model will serve as the foundation to develop a mobile application system that can benefit users, especially adolescents, in self-diagnosing depression.
\end{abstract}

Keywords - Adolescent depression; adolescent motivation; gamification; model development; human-computer interaction

\section{Introduction}

Depression is a critical public health problem, mainly when it affects young people (adolescents). According to [1], depression problems affecting adolescents are more challenging to handle than that of children and adults due to the rapid growth of physical, intellectual, and emotional development in the former group. The World Health Organization [2] reported that more than $7 \%$ of adolescents worldwide (between the ages of 15 and 19) suffered from depression in 2017. In Malaysia, between $15.8 \%$ to $21.4 \%$ of adolescents aged 13 to 17 suffered from depression [3]. One study [3] reported several factors contributing to depressive symptoms among adolescents, in- 
cluding parental separation, drug abuse, alcohol consumption, bully victim, abuse sufferer, and smoking.

Depression should be detected from an early stage to be curbed and overcome immediately [4]. The patient must undergo a diagnosis to assess mental health, followed by referral to a mental health professional [5]. However, according to [6], many individuals do not undergo diagnosis out of embarrassment, or because they are entirely unaware of their problems, so any depression symptoms go undetected for quite some time. Many psychology and sociology studies have indicated teenagers as being the most susceptible to depression [7]. According to [7], adolescence is a critical stage that significantly influences one's growth, confidence, and life choices. The effects of depression can extend beyond the adolescent phase to affect the rest of one's life if left untreated.

Depression among adolescents is most challenging to detect because it tends to worry about others' perceptions of them [8]. According to [8], some adolescents feel that they will suffer adverse effects and that their future will be compromised if labeled as depressed. This assumption will hinder the detection of depression and the necessary recovery process. Moreover, adolescents tend not to seek face-to-face treatment due to the stigma surrounding mental health care $[9,10]$. Depression causes adolescents to experience emotional changes such as despair, loss of interest in any activity, lack of self-confidence, and low self-esteem [2], ultimately demotivating them from undergoing any diagnosis for depression at a medical institution. Still, early diagnosis is essential in detecting depression among adolescents to receive help from professionals [11] immediately. The current study implemented the gamification technique to motivate adolescents to undergo depression diagnosis.

According to one study [12], the gamification technique is now commonly applied in the mental health field and is perceived as a promising new method to influence behavioral change. Gamification positively affects motivation level and guarantees continuous engagement [13]. Previous studies have reported gamification positively impacting mental health and wellbeing, besides reducing stress, anxiety, and depression $[12,14,15,16,13]$. Gamification has also been proven effective at enhancing adolescent motivation [17]. According to another study [18], digital games have become an essential part of leisure life among adolescents and are the most widely used social interaction method. A gamification-based system can motivate adolescents to diagnose whether or not they have depression. The system design should be developed to be compatible with the user to prevent boredom and ensure continuous engagement. Gamification elements implemented into a system must be following the system's focus, target, and user.

The objective of this study is to motivate adolescents to engage with a depression diagnosis system continuously. This study was conducted specifically for adolescents in secondary school prone to depressive symptoms but are not motivated to undergo diagnosis, not to mention treatment. This study collected data to identify the factors that would motivate adolescents to undergo depression diagnosis. These factors were then analyzed to determine the elements required to develop a depression diagnosis model. The proposed model applies gamification design, which involves gamification elements, user types, and motivational elements. In future studies, the model will be 
applied to develop a depression diagnosis application system. The gamification design elements were designed based on the survey findings on motivation enhancement factors among adolescents and previous literature work.

The rest of the paper is organized as follows: Section 2 provides the literature review, which includes current technological intervention methods for diagnosing depression, the factors that motivate adolescents to undergo diagnosis, gamification elements, user types, motivational elements, and the theories underpinning gamification. Section 3 explains the study methodology. Section 4 presents the study results. Finally, Section 5 and Section 6 present the discussion and conclusion, respectively.

\section{$2 \quad$ Literature Review}

Depression is a state of emotional difference that stress causes on a person's thinking style, such as the perception of self, life, and surroundings [19]. Adolescents that have undergone trauma tend to have depressive symptoms. They tend to self-isolate, are emotionally stressed, have suicidal ideation, and even attempt suicide [10]. The World Health Organization [2] reported that depression is becoming the main contributor to suicide, with nearly 800,000 cases reported yearly worldwide. Approximately $50 \%$ of adolescents are affected by suicidal ideation, but actual suicide attempts are more frequent in female adolescents, while males tend to commit suicide outright [20]. Mental health problems among adolescents are expected to increase to $13.4 \%$, but the frequency of requesting help or treatment is still low [5]. Therefore, it is crucial to self-detect depression among adolescents to curb potential suicides before it is too late.

Traditional face-to-face assessments to diagnose depression are still the most prominent method nowadays. However, this method is considered challenging, as it fails to attract adolescents with depression symptoms to go for consultation sessions $[9,10]$. A study showed that adolescents in school are motivated to learn if they are presented in an interactive gamification method rather than conventionally [21]. Thus, applying gamification in a mobile application for diagnosing depression could motivate adolescents to undergo diagnosis. Moreover, technological intervention allows this group to use the application anywhere they desire without restrictions or boundaries [21]. Therefore, this study aims to identify the factors that can motivate adolescents to self-diagnose depression.

\subsection{Technological intervention through computerized cognitive-behavioural therapy (CCBT)}

Various studies have used several technological interventions to detect and treat depression, including Computerized Cognitive-Behavioural Therapy (CCBT) methods. Technology applications satisfy the user experience (UX) and effectively enhances user engagement via user and machine [22]. Furthermore, recording data using technology during the diagnosis process can give various advantages. The comple- 
menting tools used to process and analyze the obtained data need to be developed carefully to draw valuable conclusions [23].

Previous studies have reported the practicality and efficiency of technological interventions in automatically detecting depressive problems based on machine learning algorithms [24,25,26,27]. In some studies, depression levels were measured using artificial intelligence (AI) through speech, voice analysis, and facial expressions [24,26], as well as video, audio, and visuals or text analysis [28,29,30]. This method has been proven effective in some studies, but the patients cannot directly use the technology produced. The patients need to get technical services from practitioners in medical institutions. The issue arises when adolescents with depression are susceptible to criticism due to feelings of worthlessness [31], causing them to avoid pursuing face-to-face treatment and consultation [32,33,9]. Therefore, this current method is not sufficient for adolescents due to the consulting activities involved.

On the other hand, the CCBT method is a technology-integrated therapy that uses a computer to diagnose depression, including therapy treatment. Patients can directly use this technology without having to see a consultant. Previous studies involving the CCBT method have also helped patients cope with depression disorders $[14,15,34,35]$. However, usability issues, unfriendly user interfaces, and limited functionality have caused users to feel disengaged from the system [36]. The main weaknesses detected in the CCBT method are the too-long therapy sessions and overwhelming content [37]. These weaknesses cause the patients to lose motivation, thus causing them to disengage from the system. Therefore, the depression diagnosis system module should be separated from the therapy module system to reduce the risk of patient dropouts. Moreover, patient motivation level could be improved by ensuring continuous engagement.

\subsection{Adolescent motivation enhancement factors}

Motivation is a fundamental element in encouraging adolescent engagement in any activity. One study [16] found that motivation is one of the principal components of addiction. Motivation indicates that highly-motivated individuals are always engaged in any activity they participate in.

The gamification technique can deliver knowledge via a fun environment [21]. In this study, adolescent motivation enhancement factors involve gamification elements, including game mechanics and game components. These elements can serve as intrinsic and extrinsic motivators that encourage users to stay motivated. According to [17], a game-based development approach can increase adolescent motivation and knowledge about certain concepts. The adolescent gamification user type must also be identified to ensure consistent adolescent motivation enhancement. The motivation elements identified from both gamification elements and user types are thus fundamental towards motivating adolescents.

Gamification Elements: The gamification principle is based on the enjoyment derived from gaming, which promotes normal behavior. This principle originates from the entertainment game industry [38]. According to [39], gamification is an essential element in improving an application system's effectiveness and encourages continu- 
ous user engagement. A previous study [40] noted various fields implementing gamification into their learning process these days. With interaction engagement, users can obtain new information or develop current knowledge and understand a specific matter [40].

Gamification elements consist of game mechanics and game components. Game mechanics are a critical element in a developer's gamification system that helps users interact with the game [41,42]. Game components help ensure continuous user engagement with the gamification system [43]. Game mechanics include challenges, opportunities, competitions, feedback, and rewards, while game components include achievements (results and progress bars or indicators), avatars, badges, leaderboards, levels, and point systems [44]. Game components aim to characterize, control, and preserve the gamification elements integrated into a system [45].

Another study [12] reported that gamification could improve participant motivation and ensure long-term involvement. It also mentioned that gamification interventions positively impact wellbeing and self-esteem and reduce stress and anxiety [12]. However, the type of dominant adolescent users must first be determined to identify the motivational elements that encourage continuous user engagement.

User Types: The gamification user type model in [46] showed that system developers would target various users controlled by different motivational elements. Gamification design development should consider the users targeted for the developed application system.

The model presents six user types: socializer, free spirit, achiever, philanthropist, player, and disruptor. Each user type in the model acts correspondingly to the identified motivational elements [46]. The socializer will interact with players to make social connections. Free spirit users will create and explore games. The achiever will always learn new things to improve themselves. They also love challenges. Philanthropist users persistently want to enrich other people's lives without expecting anything in return. Players will do anything to reward themselves, while disruptors are those individuals who wish to disrupt the system to force changes. These user types are derived from different types of players, including self-seekers, exploiters, networkers, and consumers, and all have the same goal of earning rewards through various means. Therefore, the motivational elements that encourage users to engage in self-diagnosing depression levels continuously must be identified based on the gamification elements and user types.

Motivational Elements: Previous studies have reported motivation influencing continuous user engagement, which, in turn, indirectly affects whether or not the desired outcome is achieved [47,48]. This study proposed a model based on several theories that support the element of motivation, which is the fundamental purpose of gamification [40]. Motivation can be identified through extrinsic rewards in-game components such as level, point system, progress indicator, and achievement badges. Extrinsic motivation can enhance user engagement while striving to increase intrinsic feelings in achieving the elements of mastery, autonomy, and maximum competency through the implementation of gamification mechanics. This element helps to achieve the targeted goal of increasing adolescent motivation to continue using a depression diagnosis application system. 
Some theories in previous gamification studies have been used as the basis for mental health studies, especially the Theory of Motivation [49], the Theory of SelfDetermination (SDT) [50], the Theory of Cognitive Evaluation (CET) [12], and the Theory Of Behavior [13]. Section 2.3 discusses the links between these theories.

\subsection{Theories underpinning gamification}

Gamified applications have mainly been used due to their theoretical ability in creating game motivational power [51]. Motivational theory [52] involves intrinsic and extrinsic motivation. Based on the Theory of Self-Determination (SDT) [52], intrinsic motivation will be increased when autonomy mastery is achieved. This opinion is in line with the Theory of Cognitive Evaluation (CET) [53], a sub-theory to SDT. To facilitate the mastery of intrinsic motivation, the foundations of competency and autonomy should be met. According to SDT, autonomy is also related to one's behavior. The Behavioral Theory [54] states that an individual's behavior depends on intrinsic and extrinsic motivation. This theory can influence changes in individual behavior if implemented together with gamification techniques.

Therefore, a theoretical model (Fig. 1) underpinning gamification was produced based on the different theories discussed above. The model integrates all four theories, where the relationship between these theories serves as the foundation for this study. According to the theoretical model, the proposed application system should use diagnostic methods based on the CCBT module to detect adolescent depression levels. The diversity of user types will influence the appropriate approaches and gamification elements selected, namely game mechanics and game components, based on the target user's intrinsic motivation. The theories that support the motivational elements form the basis of the proposed model. As mentioned before, motivation is identified through extrinsic rewards offered by the game components. Game mechanics enhance user engagement and encourages intrinsic feelings driven by intrinsic motivation. Both gamification elements were implemented to achieve the targeted goal of improving adolescent motivation to engage in self-diagnosing depression continuously. 


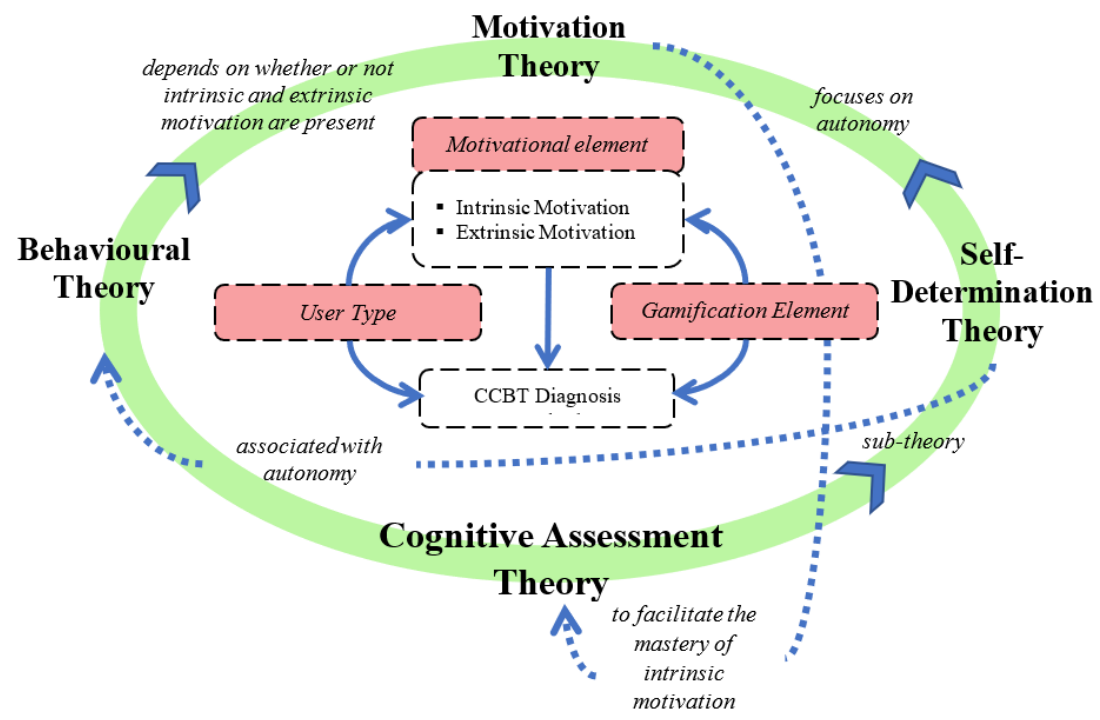

Fig. 1. Theoretical model

\section{Methodology}

In this study, we conducted a survey based on the theoretical model in Fig. 1. The purpose of our study is to identify the factors that motivate adolescents to undergo depression diagnosis. We collected the data for this study by administering a questionnaire on adolescents in secondary school. Information on the factors that can enhance adolescent motivation to ensure continuous engagement was gathered in this phase. The obtained data were then analyzed to determine the gamification design elements to help develop the depression diagnosis model.

\subsection{Participants}

The sample for this study was chosen using non-probability purposive sampling. The respondents consisted of secondary school students aged 13 to 17 years. The survey study was conducted by distributing questionnaires to $N=53$ (15 males, 38 females) students in Port Dickson, Malaysia. The respondents were asked to read and verify the research consent form before answering the test privately, according to their knowledge, without their friends' or teacher's help. The total time given was 30 minutes. The students were also given some time to review all the questions to ensure no data dropout or incomplete answers. 


\subsection{Instrument}

The questionnaire in this study consists of 3 sections. Section A contains the respondent demographic information, including gender, age, ethnicity, history of depression, and the choice of depression screening medium. Section B assesses adolescent motivation enhancement factors constructed based on adaptation and modification from the previous study: Intrinsic Motivation in Gamification [55]. Section C assesses the gamification user types adapted and modified from the previous study: HEXAD Gamification User Type Questionnaire: Background \& Development Process [56].

For Section B, items adapted from [55] were modified into three constructs according to game mechanics, including challenges, rewards, and feedback. A total of 15 items were constructed, with each motivational construct consisting of five items. Each item was rated according to the 5-point Likert scale, which is 1 - Very Not Important to 5 - Very Important.

Section C presents adapted questionnaire items from a previous study [56] that identify intrinsic motivation based on user type. The constructs studied are users in the HEXAD model [46], consisting of players, achievers, philanthropists, socializers, free spirits, and disruptors. The application system can be developed based on the dominant user type among adolescents with user psychological methods without directly asking the user to list the game design elements [57]. Initially, a total of 30 items were prepared, where each construct consisted of 5 items. Each item was rated according to the 7-point Likert scale, 1 - Strongly Disagree to 7 - Strongly Agree.

\section{$4 \quad$ Results}

This section is divided into two. Section 4.1 presents the pilot study findings, which are used to determine the reliability and validity of the developed instrument, while Section 4.2 presents the findings of the actual survey study and the analysis of the adolescent motivation enhancement factors. The data were analyzed using IBM SPSS Statistics V.25 software and presented in tabular and text format. We used Pearson's Correlation Coefficient to present the Correlations between the variables in this study.

\subsection{Pilot study}

The pilot study was conducted on $N=38$ adolescents at a secondary school in Port Dickson, Malaysia. These pilot study participants did not participate in the actual study. This pilot study aimed to obtain reliability and validity for the questionnaire instrument by determining Cronbach's alpha coefficient [58]. The researcher was also able to identify the respondents' time to answer all the questionnaire items and ensured that the instrument content was understandable. The respondents took 25-30 minutes to complete the questionnaire. 
To determine whether the constructed items should be accepted or discarded, the researcher compared the value of 'Alpha if Item Deleted' for each item based on the Cronbach's alpha value of the constructs involved in the instrument. According to [59], if an item in a construct has a higher alpha value if the item was deleted, compared to the value of Cronbach's alpha for that construct, the item must be discarded.

The Cronbach's alpha values ranged from 0.677 to 0.804 for Section B and 0.491 to 0.812 for Section C. For Section B, the highest Cronbach's alpha value was 0.804 for the feedback construct, while the lowest Cronbach's alpha value was 0.677 for the challenges construct. Section C recorded the highest Cronbach's alpha value on the socializer construct at 0.812 , while the lowest Cronbach's alpha value was 0.491 for the Disruptor construct. Meanwhile, the results showed that the overall Cronbach's alpha value for this questionnaire instrument was 0.882 and 0.873 for Section B and Section C, respectively. This result indicates that the questionnaire instrument has high reliability.

However, two items from Section C were identified to have very low-reliability; ' $I$ care about my wellbeing only' (Players), and 'I like to question the rules or laws that have been enacted' (Disruptor). A total of 6 items from Section $\mathrm{C}$ were discarded, significantly impacting the reliability coefficient value $(\leq 0.100)$. Finally, after going through the refinement process, each construct was left with four items.

\subsection{Actual study}

After updating and improving the questionnaire items based on the pilot study findings, the actual study was conducted on $N=53$ ( $M$ age $=14.32$ years, $S D$ age $=1.252$ years) students studying in a secondary school at Port Dickson, Malaysia. The participants were of different ethnicities, including Malay (32.1\%), Chinese (26.4\%), Indian (39.6\%), and others (1.9\%), with $28.3 \%$ males and $71.7 \%$ females between 13 and 16 years old.

Through this survey, a total of 16 out of 53 respondents (30.2\%) who participated were not sure whether they had ever experienced depression. In contrast, a total of $26.4 \%$ of the respondents admitted that they had experienced depression before, and the remaining $43.4 \%$ claimed that they never had depression.

A total of 23 participants (43.4\%) agreed that the game-based depression diagnosis medium was their preferred choice compared to seeing a doctor or psychologist faceto-face in clinics and hospitals (35.8\%) or using on-line screening systems (20.8\%).

The analysis of the results (Table 2) after applying appropriate statistical tests showed that a total of $75.5 \%$ of the adolescents in this study agreed that the elements in the challenges were the most significant factor that enhanced their motivation, with the highest mean of 4.04, compared to factors from the rewards element $(58.9 \%$, mean $=3.58)$ and feedback element $(47.2 \%, \min =3.44)$. An item from the element of the challenge: 'I need to master a skill to achieve the goal that I want', received the highest response from the participants $(85.9 \%$, min 4.17), while an item from the rewards element received the lowest response: 'I need to get rewarded in every activity I participate in' $(30.2 \%, \min =3.42)$. 
The findings also indicate that the adolescents are more prone to becoming philanthropist users, where $72.6 \%$ responded with the highest mean of 5.43 , followed by the free spirit users $(67.4 \%$, mean $=5.27)$ and achievers $(66.0 \%$, mean $=5.26)$. The socializer, player, and disruptor received fewer responses of $51.0 \%, 42.0 \%$, and $21.7 \%$, respectively, with means of $4.51,4.18$, and 3.04, respectively. An item from the philanthropist users received the highest response from the participants $(83.0 \%$, $\mathrm{min}=$ 6.11): 'I would be happy if I could help others', while an item from the disruptor users achieved the lowest response $(11.4 \%, \min =2.49)$ : 'I like to provoke others'.

Table 1. Analysis of Adolescent Motivational Enhancement Factors

\begin{tabular}{|l|l|c|c|}
\hline \multicolumn{2}{|c|}{ Adolescent Motivational Enhancement Factors } & \multicolumn{2}{c|}{ Respondent (N = 53) } \\
\cline { 3 - 4 } & \multirow{4}{*}{ Intrinsic Motivation } & Mean & Response \% \\
\hline \multirow{5}{*}{ User Type } & Challenges & 4.04 & 75.5 \\
\cline { 2 - 4 } & Rewards & 3.58 & 58.9 \\
\cline { 2 - 4 } & Feedback & 3.44 & 47.2 \\
\hline & Socializer & 4.51 & 51.0 \\
\cline { 2 - 4 } & Philanthropist & 5.43 & 72.6 \\
\cline { 2 - 4 } & Free Spirit & 5.27 & 67.4 \\
\cline { 2 - 4 } & Achiever & 5.26 & 66.0 \\
\cline { 2 - 4 } & Disrupter & 3.04 & 21.7 \\
\cline { 2 - 4 } & Player & 4.18 & 42.0 \\
\hline
\end{tabular}

In sum, these findings show that the challenges are the most crucial element of game mechanics that can determine the application system's effectiveness and should therefore be prioritized when developing the depression diagnosis model for the identified dominant user types: philanthropist, free spirit, and achiever.

\subsection{Correlation between variables}

The correlation value between the variable 'Philanthropist' and the variables: "Challenges" were statistically significant $(r=0.521, \mathrm{p}=0.000)$, "Rewards" were statistically significant $(\mathrm{r}=0.596, \mathrm{p}=0.000)$, "Feedback" was statically significant ( $\mathrm{r}$ $=0.553, \mathrm{p}=0.000)$. The correlation value between the variable 'Free Spirit' and the variables: "Challenges" were statistically significant $(r=0.567, p=0.000)$, "Rewards" were statistically significant $(r=0.430, p=0.001)$, "Feedback" was statically significant $(\mathrm{r}=0.443, \mathrm{p}=0.001)$. The correlation value between the variable 'Achiever' and the variables: "Challenges" were statistically significant $(r=0.701, p=0.000)$, "Rewards" were statistically significant $(r=0.716, p=0.000)$, "Feedback" was statically significant $(r=0.740, p=0.000)$. The high Correlation Coefficients indicate that there is a close relationship between the three most dominant user types, which were identified from the questionnaire test administered on the adolescents (Section C: User Types) and the indicators of adolescent motivational enhancement factors. 


\section{Discussion}

The responses to the depression diagnosis medium in the Demographics section of the survey showed that $43.4 \%$ of participants were interested in self-diagnosing depression using a game-based application screening system. This is supported by a recent study, which reported that adolescents in school found it easier to be part of a game-based educational process, as they could use different aspects of technology fluently [21]. This current study's findings show that intrinsic motivations from the challenges construct, which is one of the game mechanics elements, received the highest response among adolescents. The challenges element can ensure the adolescents' continuous engagement due to enhanced motivation to achieve intrinsic satisfaction. However, all game mechanics need to be merged before the diagnosis depression model can be developed to produce an application system that can enhance motivation through the user gaming experience [44]. Challenges are the critical element in improving adolescent intrinsic motivation, while rewards and feedback elements can satisfy the adolescents' intrinsic feelings. These marks are also consistent with another study, suggesting that a well-designed gamification application, integrating emerging game mechanics and game components, helped increase motivational outcomes [51].

Intrinsic feelings are achieved via the mastery of extrinsic motivation based on the game components' functions applied in the system. As per [40], game components can develop users' extrinsic motivation and increase their engagement. Table 2 below lists a functional description of the game mechanics [44] involved in forming the depression diagnosis model and the appropriate game components to represent each mechanic.

Table 2. Game Mechanics [44] and Game Components

\begin{tabular}{|l|l|c|}
\hline Game Mechanics & \multicolumn{1}{|c|}{ Description } & \multicolumn{1}{|c|}{ Game Component } \\
\hline Challenges & Puzzles or tasks that require effort to solve & $\bullet$ \\
\hline Rewards & Benefits derived from the actions taken or achievements & $\begin{array}{l}\text { Point System } \\
\text { Achievement } \\
\text { Badges }\end{array}$ \\
\hline Feedback & $\begin{array}{l}\text { Information on the current state or progress of the } \\
\text { player }\end{array}$ & $\begin{array}{l}\text { Progress Indica- } \\
\text { tors }\end{array}$ \\
\hline
\end{tabular}

The findings also indicate that the dominant user types among the participating adolescents who achieved the highest response in this study are philanthropists, free spirits, and achievers. These findings are in line with [60], who discovered that one of the strongly correlated types of users among adolescents is philanthropists. Different intrinsic motivations drive each type of user. The philanthropist users are motivated by purpose, free spirit users are encouraged towards autonomy, while achiever users are inspired by mastery [46]. The game components involved serve as the system's functions and features based on the identified dominant users and their intrinsic motivation. It helps in achieving adolescent extrinsic satisfaction towards the developed application system. The optional app sharing function should also encourage the 
philanthropist user's extrinsic feelings. Table 3 presents a description of the motivational elements and the identified dominant user types [46].

Table 3. Dominant User Types among Adolescents and its Motivational Elements [46]

\begin{tabular}{|c|c|c|c|}
\hline User Type & $\begin{array}{c}\text { Intrinsic } \\
\text { Motivation }\end{array}$ & Description & Extrinsic Motivation \\
\hline Philanthropist & Purpose & $\begin{array}{l}\text { Always wants to give something to others } \\
\text { without expecting anything in return. }\end{array}$ & - $\quad$ Sharing Option \\
\hline Free Spirit & Autonomy & Loves to create and explore. & $\begin{array}{ll}- & \text { Progress Indicators } \\
\text { - } & \text { Level } \\
\end{array}$ \\
\hline Achiever & Mastery & $\begin{array}{l}\text { Always wants to learn something new to } \\
\text { improve self-abilities and to be the best at } \\
\text { things. Loves challenges. }\end{array}$ & $\begin{array}{ll}\text { - } & \text { Point System } \\
\text { - } & \text { Achievement Badges } \\
\text { - } & \text { Progress Indicators } \\
\text { - } & \text { Level } \\
\end{array}$ \\
\hline
\end{tabular}

Table 4 shows the gamification design elements that were determined for developing the depression diagnosis model based on the gamification technique.

Table 4. Gamification Design Elements

\begin{tabular}{|c|c|}
\hline Gamification Design & Elements \\
\hline \multirow[t]{2}{*}{ Gamification Element } & $\begin{array}{c}\text { Game Mechanics } \\
\text { Challenges } \\
\text { Rewards } \\
\text { Feedback } \\
\end{array}$ \\
\hline & \begin{tabular}{|l} 
Game Components \\
Point System \\
Progress Indicator \\
Level \\
Achievement Badges
\end{tabular} \\
\hline \multirow[t]{3}{*}{ User Type } & Philanthropist \\
\hline & Free Spirit \\
\hline & Achiever \\
\hline \multirow[t]{2}{*}{ Motivational Element } & $\begin{array}{r}\text { Intrinsic Motivation } \\
\text { Purpose } \\
\text { Autonomy } \\
\text { Mastery }\end{array}$ \\
\hline & $\begin{array}{l}\text { Extrinsic Motivation } \\
\text { Sharing Option } \\
\text { Game Components }\end{array}$ \\
\hline
\end{tabular}

The proposed depression diagnosis model based on the gamification technique is shown in Fig. 2. The formation of this model is in line with the theoretical model discussed in Fig. 1. The same goal of the gamification design elements in building the model is to be achieved, which is to enhance the adolescents' motivation level in order to engage them to continue using the game-based mobile application depression diagnosis system. This finding is supported by a recent study, which found that adolescents in school who were involved in game-based learning felt they had more engagement and increased motivation to participate in the learning process [18]. The theoretical model outlined various user types and gamification elements consisting of 
game mechanics and game components that need to be applied in the model formation.

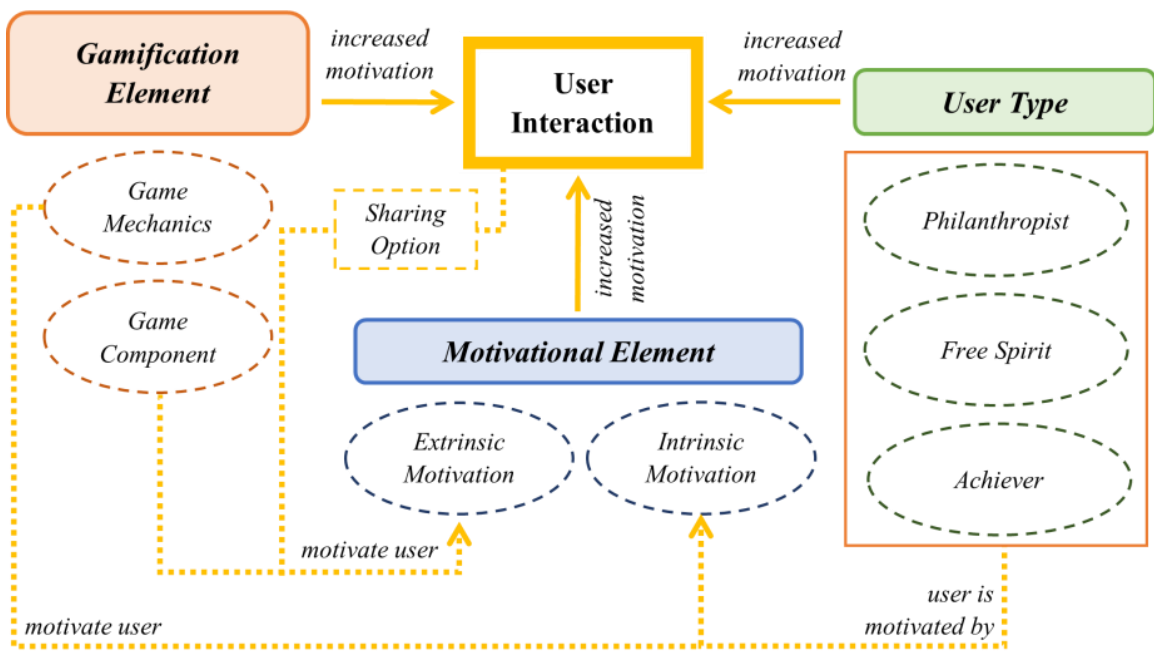

Fig. 2. Proposed depression diagnosis model based on the gamification technique

Based on the proposed model, the game mechanics elements that will be implemented in the diagnosis application system will encourage users' enhanced intrinsic motivation. It will consist of a set of challenges that the user can solve optionally. Simultaneously, the system will measure the level of user depression based on the choices made in the diagnosis session. The collected rewards are based on the challenges that the users successfully solve, while the feedback is the diagnosis results of the user's depression level.

Functions and features that trigger extrinsic motivation need to be incorporated into the depression diagnosis application system. This can be done by applying suitable game components to ensure the intrinsic satisfaction of each user type. Based on the game mechanic elements, a list of appropriate game components was identified, including the point system, progress indicator, levels, and achievement badges. These game components are the gamification element that gives extrinsic motivation to enhance the engagement of different adolescent user types, including via an optional app sharing function. The game components are the gamification functions that will be included in the mobile application system development.

A particular style of intrinsic motivation was derived from the identified gamification user types. The identified dominant user types are each encouraged by intrinsic motivation: philanthropist-purpose, free spirit-autonomy, and achiever-mastery. These elements are from the intrinsic motivation element incorporated in the SelfDetermination Theory (SDT) [57], which was used to construct the gamification user type model [46]. According to the gamification methods, combining intrinsic motivation and extrinsic motivation using the identified game components can increase user 
engagement [52]. Therefore, the proposed model was built by combining all the relevant motivational elements to increase adolescent motivation.

This study proposes a model for designing a depression diagnosis mobile application system that could help adolescents be aware of their mental health state and get the right treatment as soon as possible, if necessary. The combination of technology and gamification can meaningfully enhance adolescent motivation to self-diagnose depression levels.

However, in this study, only some basic descriptive statistical methods were used for the data analysis. In future research, we intend to use more advanced statistical tools that include comparisons and interactions between multiple variables or finding latent variables for a set of factors.

\section{Conclusion}

Depression disorder can bring various adverse effects to the life of an individual, especially adolescents. Routine diagnosis to identify depressive symptoms in adolescents is essential for early detection and immediate intervention [4]. This study was conducted to identify the factors that enhance adolescent motivation to undergo depression diagnosis. The findings were used to form a depression diagnosis model based on a gamification technique to ensure continuous adolescent engagement. It is consistent with a previous study [51] that the use of the gamification method boosts students' motivation and engagement and contributes positively to the growth of adolescents' interest and attitudes at schools [18].

The proposed model will form the basis for developing a gamified mobile application system that can benefit adolescents' self-diagnose depression levels. With the widespread use of smartphones, it is believed that mobile technology applications developed to achieve mental health goals can enhance the quality of mental health care received, including minimizing stigma and improving treatment accessibility [61]. Moreover, the gamification method can improve the player's awareness of a specific topic and help change its attitude and perspective of this topic [23]. To conclude, the depression diagnosis application system based on the gamification technique can motivate adolescents and increase their awareness about mental health care. The diagnosis results and the reports must be available to the users for selfenhancement and self-evaluation [40].

Despite the number of limitations in this study (insufficient sample size, time constraints, basic statistical methods, etc.), it still proves that the gamification method can increase motivation and ensure continuous user engagement [13]. The use of gamification approaches is a continuous educational interest concept [23] and capable of delivering knowledge via a fun environment [21]. However, this study emphasized the model formation and determination of gamification design by focusing only on data collection and data analysis. Therefore, a future study will focus on the model's usability testing via cognitive walkthrough evaluation methods. Expert users will also evaluate a moderate-fidelity depression diagnosis application system prototype. Moreover, the evaluators' evaluation and feedback will be used to validate and deter- 
mine the constructed model's usability level, thus improving the proposed depression diagnosis model.

\section{$7 \quad$ Acknowledgement}

The authors would like to thank Universiti Kebangsaan Malaysia (UKM) for funding this research under the Research Initiative Grant Scheme FRGS/1/2019/ICT04/UKM/02/1

\section{$8 \quad$ References}

[1] R. A. Salam, J. K. Das, Z. S. Lassi, and Z. A. Bhutta, "Adolescent Health Interventions: Conclusions, Evidence Gaps, and Research Priorities," J. Adolesc. Heal., vol. 59, no. 2, pp. S88-S92, 2016, https://doi.org/10.1016/j.jadohealth.2016.05.006

[2] WHO, "Depression and other common mental disorders: global health estimates," World Health Organization, 2017

[3] I. K. U. KKM, "The National Health and Morbidity Survey 2017: Adolescent Mental Health (DASS-21)," 2017.

[4] A. Nyundo et al., "Factors associated with depressive symptoms and suicidal ideation and behaviors amongst sub-Saharan African adolescents aged 10-19 years: a cross-sectional study," Trop. Med. Int. Heal., vol. 25, no. 1, pp. 54-69, 2020, https://doi.org/10.1111/ $\underline{\text { tmi. } 13336}$

[5] N. Ibrahim et al., "Do depression literacy, mental illness beliefs and stigma influence mental health help-seeking attitude? A cross-sectional study of secondary school and university students from B40 households in Malaysia," BMC Public Health, vol. 19, no. Suppl 4, pp. 1-8, 2019, https://doi.org/10.1186/s12889-019-6862-6

[6] L. Tong, Xiangrong, Q. Zhang, A. Sadka, L. Li, and H. Zhou, "Inverse boosting pruning trees for depression detection on Twitter," pp. 1-15, 2019.

[7] L. Zhu, "A multi-level analysis on school connectedness, family support, and adolescent depression: Evidence from the National Longitudinal Study of Adolescent Health, 19951996," Soc. Sci., vol. 7, no. 5, 2018, https://doi.org/10.3390/socsci7050072

[8] L. Dolphin and E. Hennessy, "Labelling effects and adolescent responses to peers with depression: An experimental investigation," BMC Psychiatry, vol. 17, no. 1, pp. 1-10, 2017, https://doi.org/10.1186/s12888-017-1389-9

[9] N. Ibrahim, A. Mohd Safien, C. S. Siau, and S. Shahar, "The Effectiveness of a Depression Literacy Program on Stigma and Mental Help-Seeking Among Adoles-cents in Malaysia: A Control Group Study With 3-Month Follow-Up,” Inq. J. Heal. Care Organ. Previs. Financ., vol. 57, pp. 1-10, 2020, https://doi.org/10.1177/0046958020902332

[10] U. C. Pendit and K. A. Choo, "Openness Towards Mental Illness in Malaysia," e-BANGI J. Sains Sos. dan Kemanus., vol. 17, no. 3, pp. 46-56, 2020.

[11] E. J. Garland and K. Solomons, "Early Detection of Depression in Young and Elderly People," BCMJ, vol. 44, no. 9, pp. 469-472, 2002, doi: 10.1007/BF00969696.

[12] D. Tolks et al., "ONYA-The wellbeing game: How to use gamification to promote wellbeing,” Inf., vol. 10, no. 2, pp. 1-7, 2019, https://doi.org/10.3390/info10020058

[13] G. Pramana, B. Parmanto, J. Lomas, O. Lindhiem, P. C. Kendall, and J. Silk, "Using mobile health gamification to facilitate cognitive behavioral therapy skills practice in child 
anxiety treatment: Open clinical trial," J. Med. Internet Res., vol. 20, no. 5, 2018, https://doi.org/10.2196/preprints.8902

[14] T. Kuosmanen, T. M. Fleming, and M. M. Barry, "The implementation of SPARX-R computerized mental health program in alternative education: Exploring the factors contributing to engagement and dropout," Child. Youth Serv. Rev., vol. 84, no. August 2017, pp. 176-184, 2018, https://doi.org/10.1016/j.childyouth.2017.11.032

[15] T. M. Fleming et al., "Maximizing the impact of E-Therapy and Serious Gaming: Time for a paradigm shift," Front. Psychiatry, vol. 7, no. APR, pp. 1-7, 2016, doi: 10.3389/fpsyt.2016.00065.

[16] S. Peracchia, F. Presaghi, and G. Curcio, "Pathologic use of video games and moti-vation: Can the gaming motivation scale (GAMS) predict depression and trait anx-iety?," Int. J. Environ. Res. Public Health, vol. 16, no. 6, 2019, https://doi.org/10.3390/ijerph16061008

[17] S. Papadakis, "Evaluating a game-development approach to teach introductory programming concepts in secondary education," Int. J. Technol. Enhanc. Learn., vol. 12, no. 2, pp. 127-145, 2020, https://doi.org/10.1504/ijtel.2020.106282

[18] S. Papadakis and M. Kalogiannakis, "Using gamification for supporting an introductory programming course. The case of classcraft in a secondary education classroom," Lect. Notes Inst. Comput. Sci. Soc. Telecommun. Eng. LNICST, vol. 229, pp. 366-375, 2018, https://doi.org/10.1007/978-3-319-76908-0_35

[19] N. A. Yahya and F. Md. Sham, "Pendekatan Tazkīyat al-nafs Dalam Menangani Masalah Kemurungan," Al-Hikmah, vol. 12, no. 1, pp. 3-18, 2020.

[20] L. N. Bakola, N. D. Rizos, and A. S. Drigas, "ICTs Supportive and Therapeutic Contribution in Psychoemotional Disorders in Childhood and Adolescence,” Int. J. Recent Contrib. from Eng. Sci. IT, vol. 6, no. 2, p. 69, 2018, https://doi.org/10.3991/ijes.v6i2.8796

[21] S. Papadakis, A. M. Trampas, A. K. Barianos, M. Kalogiannakis, and N. Vidakis, "Evaluating the learning process: The 'thimeledu' educational game case study," CSEDU 2020 Proc. 12th Int. Conf. Comput. Support. Educ., vol. 2, no. January, pp. 290-298, 2020, https://doi.org/10.5220/0009379902900298

[22] T. S. M. Tengku Wook et al., "User Experience Evaluation Towards Interface De-sign of Digital Footprint Awareness Application,” Asia-Pacific J. Inf. Technol. Multimed., vol. 09, no. 01, pp. 17-27, 2020, https://doi.org/10.17576/apjitm-2020-0901-02

[23] N. Vidakis, A. K. Barianos, A. M. Trampas, S. Papadakis, M. Kalogiannakis, and K. Vassilakis, "Generating education in-game data: The case of an ancient theatre serious game," CSEDU 2019 - Proc. 11th Int. Conf. Comput. Support. Educ., vol. 1, no. April, pp. 36-43, 2019, https://doi.org/10.5220/0007810800360043

[24] S. Dham, A. Sharma, and A. Dhall, "Depression Scale Recognition from Audio, Visual and Text Analysis," 2017.

[25] E. W. McGinnis et al., "Giving Voice to Vulnerable Children: Machine Learning Analysis of Speech Detects Anxiety and Depression in Early Childhood," IEEE J. Biomed. Heal. Informatics, vol. 23, no. 6, pp. 2294-2301, 2019, https://doi.org/10.1109/jbhi.2019.2913590

[26] A. Haque, M. Guo, A. S. Miner, and L. Fei-Fei, "Measuring Depression Symptom Severity from Spoken Language and 3D Facial Expressions," pp. 1-7, 2018.

[27] M. Cukic, D. Pokrajac, M. Stokic, slobodan Simic, V. Radivojevic, and M. Ljubisavljevic, "EEG machine learning with Higuchi fractal dimension and Sample Entropy as features for successful detection of depression," 2018.

[28] H. Dinkel, M. Wu, and K. Yu, "Text-based Depression Detection: What Triggers an Alert," pp. 6-10, 2019. 
[29] B. Shickel, S. Siegel, M. Heesacker, S. Benton, and P. Rashidi, "Automatic Detection and Classification of Cognitive Distortions in Mental Health Text," pp. 1-12, 2019. https://doi. org/10.1109/bibe50027.2020.00052

[30] A. Ray, S. Kumar, R. Reddy, P. Mukherjee, and R. Garg, "Multi-level attention network using text, audio and video for depression prediction," AVEC 2019 - Proc. 9th Int. Audio/Visual Emot. Chall. Work. co-located with MM 2019, pp. 81-88, 2019, https://doi.org/10.1145/3347320.3357697

[31] WFMH, "World Federation for Mental Health (WFMH)," 2018.

[32] D. I. Lubman et al., "Australian adolescents' beliefs and help-seeking intentions towards peers experiencing symptoms of depression and alcohol misuse," BMC Public Health, vol. 17, no. 1, pp. 1-12, 2017, https://doi.org/10.1186/s12889-017-4655-3

[33] L. S. Woon, S. I. Khoo, A. Baharudin, and M. Midin, "Association between insight and internalized stigma and other clinical factors among patients with depression: A cross-sectional study," Indian J. Psychiatry, vol. 62, no. 2, p. 2020, 2020. https://doi.org/10.4103/psychiatry.indianjpsychiatry_612_19

[34] V. Martínez et al., "Computer-Assisted Cognitive-Behavioral Therapy to Treat Adolescents With Depression in Primary Health Care Centers in Santiago, Chile: A Randomized Controlled Trial," Front. Psychiatry, vol. 10, no. July, pp. 1-11, 2019, https://doi.org/10. 3389/fpsyt.2019.00552

[35] S. Rennick-Egglestone, S. Knowles, G. Toms, P. Bee, K. Lovell, and P. Bower, "Health technologies 'in the wild': Experiences of engagement with computerised CBT," Conf. Hum. Factors Comput. Syst. - Proc., vol. 2016, no. May, pp. 2124-2135, 2016, https://doi.org/10.1145/2858036.2858128

[36] F. Purnama Sari and N. Sahari Ashaari, "Usefulness Model for The Redesign of Graduate's Student Management Information System," Asia-Pacific J. Inf. Tech-nol. Multimed., vol. 06, no. 01, pp. 100-114, 2017, https://doi.org/10.17576/apjitm-2017-0601-08

[37] B. Wright et al., "Computerised cognitive-behavioural therapy for depression in adolescents: Feasibility results and 4-month outcomes of a UK randomised con-trolled trial," BMJ Open, vol. 7, no. 1, 2017, https://doi.org/10.1136/bmjopen-2016-012834

[38] K. Puritat, "Enhanced knowledge and engagement of students through the gamifi-cation concept of game elements,” Int. J. Eng. Pedagog., vol. 9, no. 5, pp. 41-54, 2019, https:// doi.org/10.3991/ijep.v9i5.11028

[39] F. L. Khaleel, N. S. Ashaari, and T. S. M. T. Wook, "The impact of gamification on students learning engagement," Int. J. Electr. Comput. Eng., vol. 10, no. 5, pp. 4965-4972, 2020, https://doi.org/10.11591/ijece.v10i5.pp4965-4972

[40] N. Vidakis, A. K. Barianos, A. M. Trampas, S. Papadakis, M. Kalogiannakis, and K. Vassilakis, in-Game Raw Data Collection and Visualization in the Context of the "ThimelEdu" Educational Game, vol. 1220. Springer International Publishing, 2020. https://doi.org/10. 1007/978-3-030-58459-7_30

[41] B. Burke, Gamify! How gamification motivates people to do extraordinary things. Gartner, inc, 2014. https://doi.org/10.4324/9781315230344

[42] M. Sicart, "Defining game mechanics," Game Stud., vol. 8, no. 2, pp. 1-15, 2008.

[43] D. Werbach, K. \& Hunter, For the win: How game thinking can revolutionize your business. Wharton Digital Press, University of Pennsylvania, 2012.

[44] K. van den Dool, "Measuring the effect of gamification on user adoption of a software application," 2016.

[45] M. T. Alshammari, "Design and learning effectiveness evaluation of gamification in elearning systems," Int. J. Adv. Comput. Sci. Appl., vol. 10, no. 9, pp. 204-208, 2019, 10.14569/ijacsa.2019.0100926. 
[46] A. Marczewski, "Gamification, Game Thinking and Motivational Design," in Game Thinking. Even Ninja Monkeys Like to Play: Gamification, Game Thinking and Motivational Design, vol. 1st Ed., no. June, 2015, p. 15.

[47] P. G. de Barba, G. E. Kennedy, and M. D. Ainley, "The role of students' motivation and participation in predicting performance in a MOOC," J. Comput. Assist. Learn., vol. 32, no. 3, pp. 218-231, 2016, https://doi.org/10.1111/jcal.12130

[48] J. Bacca-Acosta and C. Avila-Garzon, "Student engagement with mobile-based assessment systems: A survival analysis,” J. Comput. Assist. Learn., no. November 2019, pp. 1-14, 2020, https://doi.org/10.1111/jcal.12475/v2/response1

[49] V. W. S. Cheng, T. Davenport, D. Johnson, K. Vella, and I. B. Hickie, "Gamifica-tion in apps and technologies for improving mental health and wellbeing: System-atic review," J. Med. Internet Res., vol. 21, no. 6, pp. 1-15, 2019, https://doi.org/10.2196/13717

[50] S. Gray, J. Robertson, A. Manches, and G. Rajendran, "BrainQuest: The use of motivational design theories to create a cognitive training game supporting hot executive function," Int. J. Hum. Comput. Stud., vol. 127, pp. 124-149, 2019, https://doi.org/10.1016/j. ijhcs.2018.08.004

[51] M. Kalogiannakis, S. Papadakis, and A. I. Zourmpakis, "Gamification in science education. A systematic review of the literature," Educ. Sci., vol. 11, no. 1, pp. 1-36, 2021, https://doi.org/10.3390/educsci11010022

[52] K. Karimi and J. Nickpayam, "Gamification from the Viewpoint of Motivational Theory," Emerg. Sci. J., vol. 1, no. 1, p. 34, 2017, https://doi.org/10.28991/esj-2017-01114

[53] C. Dahlstrøm, "Impacts of gamification on intrinsic motivation," pp. 1-11, 2017.

[54] D. Schoech, J. F. Boyas, B. M. Black, and N. Elias-Lambert, "Gamification for Behavior Change: Lessons from Developing a Social, Multiuser, Web-Tablet Based Prevention Game for Youths," J. Technol. Hum. Serv., vol. 31, no. 3, pp. 197-217, 2013, https://doi.org/10.1080/15228835.2013.812512

[55] D. Nedergard, "Internal motivation in Gamification An intervention study in an exercise context," 2016. [Online]. Available: http://www.diva-portal.org/smash/record.jsf?pid=diva 2\%3A939900\&dswid $=3768$

[56] L. Diamond, G. F. Tondello, A. Marczewski, L. E. Nacke, and M. Tscheligi, "The HEXAD Gamification User Types Questionnaire: Background and Development Process," in Workshop on Personalization in Serious and Persuasive Games and Gamified Interactions, 2015, no. October.

[57] R. M. Ryan and E. L. Deci, "Self-Determination Theory and the Facilitation of Intrinsic Motivation, Social Development, and Wel-Being,” Am. Psychol., vol. 55, no. 1, pp. 68-78, 2000, https://doi.org/10.1037/0003-066x.55.1.68

[58] L. C. Hin, Penyelidikan Pendidikan: Pendekatan Kualitatif dan Kuantitatif. Selan-gor: McGraw-Hill (Malaysia), 2007.

[59] C. Y. Piaw, Kaedah dan statistik penyelidikan: Kaedah penyelidikan buku 1. Se-langor: McGraw-Hill (Malaysia), 2006.

[60] J. Ooge, "Tailoring Gamification for Adolescents: a Validation Study of Big Five and Hexad in Dutch," in CHI PLAY '20, November 2-4, 2020 Virtual Event, Canada, 2020, https://doi.org/10.1145/3410404.3414267

[61] A. Stathopoulou et al., "Mobile assessment procedures for mental health and literacy skills in education," Int. J. Interact. Mob. Technol., vol. 12, no. 3, pp. 21-37, 2018, doi: 10.3991/ijim.v12i3.8038. 


\section{Authors}

Nurul Fasihah Jamaludin is a secondary-school teacher specializing in Computer Science Fundamentals. She is also a postgraduate student currently pursuing a Master's in Information Technology (Multimedia) at Universiti Kebangsaan Malaysia (UKM). She has received a full sponsorship - Federal Full Scholarship and Leaveby the Ministry of Education, Malaysia, for her current studies. She completed a Bachelor's Degree in Education (Information Technology) in Universiti Putra Malaysia in 2010.

Tengku Siti Meriam Tengku Wook works at Universiti Kebangsaan Malaysia (UKM), serving as the Head of the Master's Program Studies at the Faculty of Information Science \& Technology and Senior Lecturer in Software Tech and Management Research Center. She specializes in Human-Computer Interaction (HCI), namely e-learning, user interaction design, usability, virtual and augmented reality, and multimedia applications. Dr. Tengku Wook has also produced five book chapters and has contributed to 10 indexed proceedings and 25 Scopus and ISI-indexed proceedings. She is a UKM graduate, receiving a Bachelor's Degree and a Master's in Information Technology from the institution in 1998 and 1999. In 2012, Dr. Tengku Wook obtained her Ph.D. in HCI from the University of Malaya, Malaysia.

Siti Fadzilah Mat Noor (Ph.D., Universiti Teknologi Malaysia) is a Senior Lecturer and a researcher at the Learning Technology and Human-Computer Interaction Research Lab Centre for Software Technology and Management, Faculty of Information Science \& Technology, Universiti Kebangsaan Malaysia (UKM). Her research interests include Multimedia Application and e-learning Technology.

Faizan Qamar was awarded a Ph.D. in Wireless Networks by the Faculty of Engineering, University of Malaya, Malaysia, in 2019. He has a BE in Electronics and an ME in Telecommunications from Hamdard University, Karachi, Pakistan, and NED University, Karachi, Pakistan. Currently, Dr. Faizan is a Senior Lecturer at the Faculty of Information Science \& Technology, Universiti Kebangsaan Malaysia (UKM). $\mathrm{He}$ is the author and co-author of numerous IEEE conference papers and ISI \& Scopus journals. Dr. Faizan is also on the review board of several IEEE conference proceedings and national \& international journals. Dr. Faizan's primary research interests are Quality of Service enhancement for future wireless networks, IoT networks, D2D communication, millimeter-wave communication, and interference management.

Article submitted 2021-01-14. Resubmitted 2021-03-11. Final acceptance 2021-03-11. Final version published as submitted by the authors. 